\title{
ORIGEN Y EVOLUCIÓN DEL VALOR *
}

\author{
A
}

\section{FILOGENIA Y ONTOGENIA}

\section{Antigüedad del valor}

El estudio de la axiología depara una circunstancia peculiar y paradójica; es quizá la más nueva y la menos conocida de las disciplinas filosóficas, a pesar de lo cual está abocada a convertirse en la más importante de ellas. En efecto, la axiología maneja una vastísima temática que se encuentra en pleno desarrollo, cubriendo diversos aspectos filosóficos y culturales de capital interés para el hombre; se trata de un complejo sistema de conocimientos que, según veremos, desbordan el interés circunscrito de la filosofía para comprender también el de las ciencias o, en términos más amplios, la totalidad del saber, la cultura y la actividad del ser humano.

Pero si bien el desarrollo sistemático de la axiología es una conquista reciente cuya mayor incidencia se encuentra en la filosoffa moderna, las nociones y actitudes comunes de la vida involucran en número prácticamente inagotable las modalidades concernientes al valor y se presentan desde la más remota antigüedad. El hombre ha experimentado siempre las necesidades básicas que generan este problema y también ha concebido las soluciones elementales que admiten desde su origen, coincidiendo con su primera afloración como ser conciente. A partir de los rudimentos que se contemplan en el albor de la cultura y la civilización, adquiere en forma paulatina las más variadas actitudes conducentes al conocimiento y la realización de los actos, obras, propósitos, etcétera, que saturan su existencia y le infunden un contenido, que reviste diversos grados de importancia, en cuya virtud realiza toda suerte de valores y valoraciones en los más diversificados aspectos de su existencia individual y colectiva.

Ast aconteció desde los remotos protorigenes de la humanidad; puede afirmarse que los primeros asomos de vida se ven acompañados por numerosos aspectos que en forma directa o indirecta conllevan la generación del valor. El surgimiento de las nociones axiológicas coincide con la aparición de la racionalidad en la especie humana, y sus primeros signos revelan de manera rudimentaria el conocimiento y la aplicación del valor, proyectado en la multitud de seres, objetos, cosas, personas, actos y circunstancias que saturan la vida; en tal virtud se promueve por doquier la creación de intereses que la estimulan a un constante desarrollo, desde los más importantes donde

- Primer capitulo del libro en preparación: Tratado de axiologia. 
se refleja el sentido profundo de su ser, hasta los más pequeños e intrascendentes que se encuentran a cada paso de la vida cotidiana. Todos ellos confieren un significado extremadamente complejo a la humana existencia $y$, en la misma proporción, al problema del valor.

\section{El valor en la historia}

La antigüedad prácticamente ilimitada que se advierte en las nociones inherentes a la actividad valorativa determina que sus huellas se pierdan en el confín de la prehistoria; este hecho contrasta con el tardio surgimiento de la axiología, que empieza a ocurrir apenas en el último tercio del siglo pasado y madura hasta mediados del actual, cuando se llega finalmente a comprender esta disciplina no sólo como una rama de la filosofía, sino como la totalidad de la filosofía misma, y más ampliamente, como la totalidad del saber humano. Esta afirmación representa una de las tesis medulares que propondremos a lo largo de nuestro trabajo y constituye una postura altamente innovadora en el contexto de la filosofía tradicional.

Por virtud de la inveterada antigüedad que se constata en las nociones rudimentarias del valor es correcto afirmar que se encuentran insitas en el cúmulo de actos y obras que ocurren constantemente. Se remontan de hecho a la época arcaica de la humanidad, pues siempre debieron existir nociones de tal índole, habida cuenta que el constante ejercicio de una actividad manifiesta inexorablemente el abigarrado pluralismo de necesidades e intereses que cubren la totalidad del vivir, lo cual constituye una condición intrascendible para garantizar la supervivencia de la especie y la constante evolución de sus facultades creativas.

Según lo que hemos dicho, el establecimiento de valores y su permanente aplicación a los problemas de la existencia representa una tarea equiparable a la realidad primordial del ser humano y al desarrollo conjunto de la humanidad; por ello, el ejercicio de la capacidad valorativa acompaña a través de la historia a las manifestaciones de la vida conciente, en la cual ciframos el aspecto netamente humano de nuestro ser; así es como desde el momento en que empezamos a vivir empezamos también a pensar y valorar. De ahí el singular interés que reviste el estudio del valor en paralelo al desarrollo del conocimiento, no sólo como un tema estrictamente filosófico, sino también como un problema científico, cultural y vital, cuya diversificada aplicación se efectúa de manera indefectible en todos los actos y momentos que saturan el decurso de la experiencia.

\section{Origen del problema}

Para llevar a cabo la tarea adjudicada a la axiología, o sea el establecimiento de una doctrina universal del valor, efectuaremos un primer análisis 
que prosigue la huella de su evolución a partir del origen que se constata desde la más remota antigüedad; este surgimiento puede cifrarse en un doble sentido: como origen filogenético o filogénico atañe a la especie, y como origen ontogenético u ontogénico incumbe al individuo. El tema que nos ocupará de inmediato consiste en desentrañar el origen y la evolución del va. lor; por lo que podrá apreciarse, dicho problema constituye el umbral para llevar a cabo el estudio de la axiología.

El análisis del valor remite inicialmente al origen filogenético, el cual coincide con el origen de la especie; en tal sentido indica el momento de mayor antigüedad donde entroncan las situaciones rudimentarias concomitantes al despunte prehistórico del género humano. Sabemos que desde sus primeras manifestaciones se ponen en juego numerosos resortes instintivos para satisfacer las necesidades de subsistencia y cumplir los intereses básicos de la vida, estrechamente ligados a las condiciones impuestas por la naturaleza. El precario estado que se presenta en el albor de la civilización se circunscribe apenas al hecho de sobrevivir, y debió superarse con el transcurso del tiempo en la medida que el hombre promovió cada vez más el enriquecimiento de sus intereses; el esquema universal que auspicia su desarrollo, consistente en otorgar satisfacción a las necesidades y los deseos, persiste invariante desde esa remota antigüedad hasta la época actual, y así prevalecerá en el futuro, pues constituye el denominador universal por excelencia en la explicación y aplicación de nuestra realidad. Diversificar y superar los actos, propósitos, necesidades y deseos, es un requisito por el cual el hombre llega a trascender la predominante influencia de los instintos y la acción inmediata de los impulsos, elevándose por encima de las nociones pragmáticas que configuran el primer asomo de la conciencia, de modo tal que pueda incorporar ideas y observaciones de orden más complejo, acompañando el conocimiento necesario para su organización en el directo vínculo con la experiencia.

De este modo, las motivaciones axiológicas se reflejan en los problemas del ser y el saber, que a su vez se manifiestan en la totalidad de la cultura y la civilización, estableciendo el estrecho paralelo que asimila el problema del valor a la corriente progresista de la vida humana. Iniciada en sus etapas elementales, desde la antigüedad que se pierde en el arcano de los tiempos, sabemos que culmina en las complejas expresiones características de la edad contemporánea; a través de los siglos y los milenios el mecanismo determinante del valor se ha desenvuelto hasta alcanzar la inconmensurable variedad y magnitud que se constata en las expresiones constitutivas de la época actual; a ello se debe que la filosofía de nuestro tiempo esté influida por el signo culminante del valor, donde la disciplina conocida especificamente como axiologia encuentra un acomodo de singular trascendencia como centro de gravedad en las doctrinas contemporáneas. Todo ello explica por qué es ahora cuando se plantea por vez primera, en su debida forma, el problema del 
valor, dispuesto a ser resuelto por la vía universal, objetiva, filosófica y científica, que define la condicionalidad básica de su planteamiento.

\section{La idea del valor}

Numerosas son las dificultades que debió vencer el hombre para remontar el nivel ocasional de los actos inconscientes e instintivos que se observan en las primeras etapas de su desarrollo, y llegar a la idea sistemática del valor; es ella la que determina el surgimiento de la axiología moderna, y en ella se cumple la necesidad de edificar una disciplina filosófico-científica que acometa la compleja problemática de los valores que produce continuamente, lo cual equivale a decir la preocupación fundamental de la naturaleza humana. Para resolverla debe el filósofo, ahora más que nunca, acompañar al hombre de ciencia en su desvelo por el conocimiento de la realidad, y a todo aquél que pueda ofrecer algún aporte significativo a la explicación de la vida, entendida en función del valor. A tal efecto, filósofos y científicos participan en una labor común, consistente en explicar lo que son y significan los valores, de manera que cada quien observa desde su peculiar atalaya la indole del problema que le corresponde, pues la temática inherente a la actividad valorativa no se circunscribe a los linderos trazados por la axiología, sino comprende, de manera más amplia, la totalidad de la cultura, la civilización, el saber $\mathrm{y}$ las formas de vida, con todas las actitudes que efectuamos en el quehacer cotidiano, pues también él se requiere para plantear y resolver esta inconmensurable temática.

Inicialmente se contempla el planteamiento del valor en sus aspectos particulares, los cuales reflejan innumerables casos donde se registra el infinito universo de los intereses que motivan los correspondientes valores. Con ello señalamos que el origen del valor se encuentra en la satisfacción de los intereses humanos, percibidos de manera ocasional o emplrica; posteriormente se dilata su dimensionalidad hasta llegar a la idea universal y autoconciente del valor, que inspira la existencia de la axiologia como disciplina filosófica. Este problema se extiende a una latitud más amplia y desemboca en la concepción universal que presenta nuestra disciplina como la conciencia totalizante y fundamento primordial de intereses y valores.

Como puede apreciarse, el problema que nos ocupa es extraordinariamente complejo, a tal grado que puede considerarse como el más extenso de todos los problemas que anidan en el saber; no se limita al campo de la axiología entendida estrictamente como una disciplina filosófica, ni siquiera a toda la filosofía integrada por el concurso de sus diversas ramas, to cual ya es bastante decir; la temática del valor engloba también los problemas que acometen las ciencias particulares, e incluso la totalidad del conocimiento que producimos constantemente, pues cada noción entraña un problema de valor. 
Este hecho se refleja en la infinita variedad de acepciones, concepciones y aplicaciones que involucran un interés para el hombre; en cada caso se contiene un aspecto concerniente a la vida que repercute en la similar noción del valor. Sobre este enfoque universal puede y debe erigirse la explicación que lleva a cabo la axiología, comprendiendo un número prácticamente ilimitado de modalidades y posibilidades; una de ellas, quizá no la más importante pero sí la primera que debe ser tratada, es la que concierne a su origen y evolución.

\section{Evolución del valor}

El problema del valor, entendido de la manera más elemental como satisfactor inmediato de necesidades y deseos, se revela como el más antiguo de los problemas que ha planteado la humanidad; el primer asomo a la vida - si es que puede fijarse alguno- debió consistir en la presentación de una necesidad y la búsqueda de su satisfacción. Desde entonces evoluciona la noción del valor a través del tiempo y recorre el complejo mundo de las expresiones vitales, desde las más rudimentarias hasta las más complejas, desde las más naturales hasta las más artificiales. Para entender cabalmente este problema es necesario proseguir la integración del valor como un proceso que comprende sinópticamente el gran número de nociones y acepciones que se incorporan de manera paulatina a lo que ahora entendemos como un sistema de vida y una filosofía en base a la noción universal del valor. La sucesión de estados que engloba su prosecución a través de los siglos y los milenios configura la evolución filogenética del valor, o sea el desarrollo que se registra en la especie humana, por conducto de las generaciones y los individuos que las constituyen; se inicia esta evolución -como hemos dicho- desde sus más remotos origenes donde entronca con los estratos de la naturaleza. A partir de entonces prosigue en forma incesante la rudimentäria experiencia preaxiológica a través del tiempo, de modo que se confun. de con el multisecular proceso de integración natural y cultural de la humanidad.

Llegando al extremo, pueden considerarse las primeras manifestaciones biológicas como el remotísimo antecedente filogenético del valor, con signos tales como el instinto de supervivencia, individual y colectivo, que se advierte en todas las especies, obedeciendo al requerimiento de subsistir. Con el transcurso del tiempo, el instinto de supervivencia llegaría a convertirse en un sistema de adaptación y superación; mediante el creciente acopio de conocimientos desembocaría en el concepto universal del valor que nosotros consideramos como el coronamiento del saber. En todo ello se refrenda el núcleo de la evolución filogenética del valor, entendido como satisfacción de nece- 
sidades y deseos, pero asume en cada etapa niveles mucho más complejos y variados que los simples requerimientos de la subsistencia biológica.

El concepto universal del valor se presenta como clave para una permanente respuesta a los intereses y acompaña al desarrollo de la humanidad, llegando a las avanzadas formas de integración que se advierten en la vida cultural. Este proceso evolutivo se contempla primordialmente en el campo del conocimiento, a cuyo efecto los rudimentos de una preconciencia instintiva rigen en el orden biológico y acusan diversas manifestaciones de la atribución generalísima que concierne inicialmente a la satisfacción espontánea de los requerimientos vitales, y ulteriormente a la producción deliberada de los intereses más complejos que exigen mayores respuestas y amplían insospechadamente el alcance del valor.

La atribución universal de implementar los satisfactores adecuados a cada necesidad se vierte en los niveles múltiples de realización que acompañan al hecho de vivir; así se constituye la actitud altamente creativa consistente en cumplir los propósitos que impulsan al deseo de progresar para satisfacer los mayores intereses que saturan la vida, empleando medios cada vez más complejos y procedimientos conducentes a su realización.

Si proseguimos en la rebusca del origen filogenético llegarfamos a la observación radical que permite interpretar los signos preaxiológicos rudimentarios como asimilables a la actividad biológica, pues en ambos casos se constata un proceso determinista derivado de los impulsos naturales que se manifiestan en paralelo a la evolución de las especies; en cada estrato evolutivo acusan ellas la incrementada facultad para promover todo género de actos y obras con un factor creciente de autonomía electiva, haciendo que sus productos sean más valiosos y deseables. Así llegamos al superior nivel de la vida donde se contemplan las obras culturales; cada paso de esta evolución acoge el necesario conocimiento que le confiere una creciente aptitud deliberativa y enriquece la capacidad de vivir, multiplicando insospechadamente sus intereses y posibilidades de satisfacción.

\section{La dualidad axiogénica}

En su primer estadio, la marcha filogenética del valor se limita a satisfacer necesidades biológicas y requerimientos elementales de subsistencia; podemos remontar el pasado hasta entroncar con las formas primigenias de vida, a cuyo efecto las ciencias naturales, particularmente la biologfa, explican de qué manera se inicia la evolución en los organismos unicelulares, y cómo ocurre al punto culminante ocupado por el hombre; los animales superiores exhiben los primeros signos que acreditan el origen rudimentario de la conciencia mediante cierto tipo de acciones especificas en las cuales se advierte la capacidad de aprendizaje. Sin embargo, la ciencia amplía el señalamiento 
de esa capacidad cuando apunta a las especies primarias y llega a los protorígenes de la actividad electiva en la cual descansa la mecánica del valor; señala a tal efecto que en los organismos elementales de la escala biológica, inclusive en los unicelulares, existen las estructuras básicas de la teleologia naturalista, como es ante todo la capacidad de distinguir e ingerir los alimentos y llevar a cabo la reproducción; esta simplísima electividad se encuentra en fusión y confusión con el determinismo causal, y así persiste en toda la escala de los seres vivos hasta llegar al hombre, donde se desarrolla insospechadamente la facultad electiva que lo capacita para actuar de acuerdo a sus propias necesidades, más allá de las que expresan el instinto individual y colectivo de sobrevivir.

En la etapa culminante de esta evolución ocurren las finalidades superiores que imponen los intereses del hombre, pues aunque son también necesidades y deseos, sólo a este nivel alcanzan el rango de intereses. Parte de ellos los elige él mismo aplicando su capacidad deliberativa y parte le son impuestos por su constitución biológica, o por el mundo externo, ya sea la naturaleza o la sociedad, pues él mismo es un ser natural y recibe la impronta de las leyes que imperan en el mundo físico y en el entorno social; de cualquier modo, aun como necesidades biosociológicas, adquieren el rango de intereses por el conocimiento que les acompaña y las facultades que participan en la conciencia. De ahf arranca la dualidad que presenta el ser humano en sus aspectos constitutivos como un individuo sujeto a la determinabilidad causal de la naturaleza y como un ser social que propicia la electividad teleológica de la conciencia; entrambos - naturaleza y sociedadgeneran los correspondientes problemas que ocupan la temática inherente al origen y evolución del valor, tal como se desenvuelve en el contexto de la axiología. Así se explica, por una parte, la presencia del aspecto material de la naturaleza humana, y por la otra, la prevalencia del desarrollo cultural que se promueve mediante la acción intensiva del espíritu.

Los principios explicativos concernientes a esta dualidad de aspectos se traducen en las leyes derivadas de la causalidad y la teleologia, o sean las modalidades rectoras de la naturaleza física y la conducta social, cuya base común está determinada por la acción decisoria de la conciencia y los intereses que en ambos casos se plantean mancomunadamente. Su exégesis científico-filosófica desemboca en los sistemas determinista y finalista, según el aspecto que reciba preponderancia; deriva el primero de la causalidad y el segundo de la teleología, pero ambos sistemas ejercen un decisivo influjo en la naturaleza y la conducta del ser humano, por cuya virtud la esencia del valor debe entenderse en el doble sentido que imbrica el origen filogenético de la naturaleza biológica y el origen ontogenético de la conducta psicológica. A partir de esta dualidad de funciones se comprenden los conceptos de filogenia y ontogenia que subyacen a la base de esta problemática; el primero, 
como expresión predominante de la naturaleza, y el segundo, como manifestación preferente de la conciencia.

\title{
B
}

\author{
EL ORIGEN FILOGENÉTICO
}

\section{Vivir y sobrevivir}

Por lo concerniente al primer aspecto, la conclusión que obtenemos induce a enfatizar que las manifestaciones filogenéticas se advierten desde los estratos evolutivos que corresponden a las especies inferiores en la escala de los seres vivos, cuyo sistema de percepción es capaz de reaccionar ante la presencia de estímulos vitales y la presión que ejerce el medio ambiente para hacer posible la vida. De esta suerte se motiva una doble capacidad de funcionamiento endógeno y exógeno que llega a sus más altas modalidades en la constitución de los animales superiores y, obviamente, en el ser humano.

Los primeros antecesores en la escala filogenética de la evolución natural son los organismos unicelulares; en ellos se constata el hecho primordial que asegura el desarrollo de la vida, consistente en "saber" procurar la satisfacción de sus necesidades primarias; por ello es posible fincar un parentesco universal en el ámbito de la naturaleza abarcando la inconmensurable familia de los seres vivos, pues la realidad misma de la vida compele a responder en forma inexorable ante la necesidad instintiva de preservarla para sobrevivir. Así se cumple el designio universal, tanto en individuos como en especies, por cuyo efecto persisten los seres en medio de condiciones adversas y triunfan en la lucha con un medio hostil, tendiendo a evolucionar mediante la satisfacción de sus necesidades y el desarrollo de sus instintos, impulsos y tendencias; de este modo se genera la asombrosa trayectoria que llega a las altas potencialidades anímicas de la humanidad después de recorrer durante miles y millones de años los estadios previos en la escala evolutiva.

Concluimos, pues, en que aun las especies más elementales poseen ya los atributos suficientes para sátisfacer las necesidades básicas que, a nivel biológico primario, se reducen a una sola: subsistir. Como parte esencial de la subsistencia se plantea el hecho de alimentarse y reproducirse; la finalidad más remota en el orden biológico estriba en la perpetuación a través de las generaciones. El requerimiento de reproducción lo cubren todos los seres vivos, de modo que la permanencia de los individuos a través de las especies, de las especies a través de las generaciones, y de las generaciones a través de los milenios, determina la evolución filogenética de la vida, cuyo nivel culminante se encuentra en la actividad conciente y creativa de los humanos. 
Ast se refrenda un hecho bastante reconocido: el hombre es producto de una evolución originada desde tiempo inmemorial y desenvuelta en grados insensibles hasta alcanzar la apoteosis de la cultura; nuestra orgullosa estirpe entronca en los mutables estratos de la naturaleza y emparenta con los animales superiores, que a la vez decienden de los inferiores, hasta llegar en forma remotísima a los organismos unicelulares que exhiben el desplante de la vida.

\section{Egoismo y altruismo}

Lo que hemos expuesto hasta ahora permite comprender cómo es y cómo se desenvuelve el origen filogenético del valor, cuya base primordial se encuentra en la evolución de la vida; sabemos en qué consiste la prolongada integración de los mecanismos que determinan el surgimiento de las actitudes y aptitudes vitales que auspician la producción de valores, y por qué el desplante filogenético se efectúa desde las manifestaciones primarias y culmina en el doble aspecto natural y espiritual que acusa el despertar de la civilización. Queremos ahora referirnos a una dinámica que ocupa toda la evolución filogenética en su interno desenvolvimiento, a base de dos fuerzas polares y antagónicas consistentes en mirar hacia uno mismo o reconocer a los demás, de lo cual derivan el egoísmo y el altruismo cuya superior expresión se localiza en el hombre.

El origen natural del valor está matizado con un visible tinte de egoísmo, pues no en balde el instinto de sobrevivir a costa de los demás se observa desde las especies inferiores y se transforma posteriormente en la sofisticada tendencia a preponderar sobre ellos. Así transitamos, en el orden natural y biogenético, por las diversas manifestaciones del egoísmo, desde el instinto de sobrevivir hasta el instinto de dominar, lo cual se conoce en el contexto sociopolítico de la civilización como instinto de poder. Obvio es que éste constituye el contrapolo axiológico del altruismo; en otras palabras, el ins. tinto egoista de poder es el reverso de la medalla que simboliza lo primitivo de la naturaleza humana, cuyo anverso exhibe la silueta altruista diseñada por la conciencia axiológica del humanismo. Por ello es que, paralelamente al egoísmo individual o grupal, se desenvuelve el sentido solidario de la especie humana y por medio de la convivencia se establece la afinidad con los demás y el deseo de ser útil, lo cual repercute en que también lo sean nuestros actos y obras aportados a la misma finalidad.

El ser humano ocupa el primer plano de importancia en la evolución filogenética, pues al mismo tiempo es creador y beneficiario de los valores; a partir de las necesidades básicas se integra la conciencia individual y colectiva, orillando a la apoteosis de la cultura cuando se erige como valor supremo la convicción solidaria de la humanidad, configurando la ideologia acendradamente humanista que propugna la realización armónica de los va- 
lores. El centro de gravedad en el humanismo de todos los tiempos está ocupado por el conocimiento y la realización de los valores que, en conjunto, integran la conciencia axiológica; así tenemos que a pesar del congénito individualismo que se encuentra en todo ser humano, siempre hay alguien dispuesto a desempeñar un papel positivo para los demás y ser un elemento de apoyo en la sociedad. De ahí deriva la comunicación y la asimilación de los valores que en forma recíproca estimulan la convivencia, a través de la cual se exaltan los valores humanos y la necesidad de su conocimiento. Mediante la conciencia axiológica, que no es sino la conciencia fomentada por conducto de los valores, se rinde tributo a la convicción de que ellos simbolizan universalmente la humanidad; también se aplica el concepto del valor a los individuos, objetos, actos y obras donde se constata su existencia, pero la humanidad entendida en su acepción ideal y universal no es otra cosa que el conjunto de valores polarizados en la conciencia axiológica, donde se recoge el conocimiento que en términos generales atañe a la existencia.

Constantemente producimos toda clase de actos y obras que exhiben un sentido positivo en la medida que contribuyen a la edificación de un sistema donde el interés personal y social coinciden al más alto nivel, admitiendo como sustrato de la vida el interés suscitado por los valores; con ello se responde al ingente principio de ubicar al individuo en la sociedad y a la sociedad en armonía con la naturaleza, lo cual representa el valor supremo de la realidad natural. Sin embargo, esta condición también se inicia a niveles inferiores y por ello se la encuentra inclusive entre los animales; se observa en ellos de manera prístina el ingente llamado instintivo de la especie para su preservación y como respuesta se obtiene la solidaridad de sus miembros. Inclusive los vegetales exhiben elementos de una organización biológica que responde indefectiblemente al instinto natural de sobrevivir y promueve las formas primarias de organización colectiva. Tal es, en suma, el valor supremo de todo lo que entraña vida, pues nada hay más importante en, por y para la vida que la preservación de la vida misma.

A esta evolución se debe el sentido solidario que se constata como uno de los signos prevalentes en la evolución filogenética del valor, lo cual ha hecho posible la convivencia de los individuos con sus semejantes en el ámbito de una realidad colectiva que culmina en la aceptación de valores comunes y el interés general por la cultura. Esa virtud de conformación axiológica auspicia las óptimas realizaciones y culmina en la justificación de los valores como núcleo de interés común en el desarrollo de la colectividad.

\section{Evolución de la conciencia}

A lo largo del cauce filogenético, el valor evoluciona paralelamente a la integración del conocimiento que en diversos niveles acompaña a todos los 
momentos de la vida; una de las conclusiones básicas que derivan de esta observación señala que la existencia adquiere plenitud en la medida que sepamos lo que somos y lo que hacemos, lo cual se designa habitualmente como tener conciencia de ser y vivir.

La conciencia se refleja en su primera etapa mediante la que llamaremos protoconciencia del valor y consiste en los rudimentos cognitivos que acompañan a los conceptos y actos elementales que ejecutamos constantemente, cuyas realizaciones son en principio de orden netamente material, pero avanzan progresivamente en condiciones cada vez más propicias hasta colocarse en el alto nivel, que comporta el auge de la conciencia y autoconciencia de los valores.

El origen natural de la protoconciencia axiológica se pierde en el arcano de los tiempos, pero su desarrollo prevalece y persistirá en el futuro, alcanzando niveles cada vez de mayor complejidad cuyo límite no puede fijarse; a ello se debe que la obra creativa de la humanidad se considere una tarea infinita. El origen filogenético de la protoconciencia instintiva llega al umbral de la vida biológica, y no es reiteración decirlo cuando se distingue de la vida psicológica, pues tanto una como la otra acusan el mismo origen, pero se divorcian al ubicarse en posiciones extremas por efecto de la evolución. En todo caso persiste el dualismo naturaleza-espíritu que se reconoce en la evolución filogenética del valor; el umbral es el mismo y se localiza en las manifestaciones primigenias de la vida.

De este modo se justifica la conclusión que obtenemos en torno al origen filogenético del valor al insertarlo en el origen mismo de la vida; según este criterio, el valor responde y corresponde a la dualidad, y al mismo tiempo a la unidad, de espíritu y materia, conciencia e instinto, humanidad y naturaleza. La actividad axiológica está vinculada a la génesis de los conflictos y las soluciones que motivan. No pretendemos, sin embargo, abundar por ahora en especificaciones naturalistas que corresponde esclarecer en otro capitulo; pero dejemos claramente sentado que la influencia de la naturaleza es decisiva para implementar una doctrina realista de la actividad axiológica, y por consiguiente, de la vida misma, pues no podría fincarse al margen del poderoso influjo que ejercen los coeficientes biológicos en todas sus manifestaciones.

\section{El género "homo"}

A partir de la conciencia que se establece en el aspecto netamente humano de la vida, se debe proseguir la huella del valor cuya evolución empieza al momento en que el hombre es capaz de superar el estado dependiente de la naturaleza y tomar parte activa en su propio desarrollo. No es diffcil entender por qué el hombre primitivo empezó a crear diversos objetos para prote- 
gerse de las acechanzas inherentes al hecho de vivir en un ambiente hostil, lleno de peligros y dificultades. Así logró, con el transcurso del tiempo, la dominación y modificación del medio, e inclusive de su propia realidad, obteniendo el mejor aprovechamiento de los recursos que en el mismo orden le fueron proporcionados por la naturaleza para someterlos a las modificaciones requeridas por su afanosa industria. Sabemos que un momento determinado de la prehistoria, el homo aprendió a manejar sus propios recursos para convertirlos en instrumentos y producir los satisfactores que corresponden a las necesidades primarias de vida; con ello inició el infinito progreso de la civilización y asumió un ritmo cada vez más intenso a base de plantear necesidades y deseos que fueron creciendo hasta procurar los satisfactores requeridos por los nuevos planteamientos, cada vez más complejos, en lo cual radica la mecánica operativa del valor.

A partir de un impreciso momento en el remoto pretérito, el ser humano empezó a desarrollar los menesteres del homo faber, el hombre que hace. Es entonces cuando, al final de una primera y prolongada etapa, el humanoide se libera de sus ataduras frente a la naturaleza y efectúa el supremo esfuerzo de creatividad que le permite manejar los materiales dados mediante los instrumentos que él mismo fabrica, multiplicando en breve lapso sus posibilidades de dominio sobre la naturaleza y posteriormente sobre sus semejantes. Desde entonces ha progresado con multitud de conquistas que exaltan su existencia hasta llegar a la apoteosis que denota el mundo de las realizaciones prácticas, al cual acompaña una paralela experiencia en la cultura. La ciencia evalúa aproximadamente en unos cien mil años el período transcurrido desde la liberación del homo faber mediante el arbitrio de los primeros instrumentos $\mathrm{y}$, acordes con esta apreciación, podemos reconocer el mismo lapso como período transcurrido en la evolución de los elementos protoaxiológicos, desde los antecedentes que corresponden al umbral de la vida conciente, hasta las manifestaciones selectivas que se observan en el homo sapiens, el cual prevalece en nuestro tiempo.

Es un hecho reconocido que con él se inicia el esplendoroso auge de la cultura. El género homo prosigue ininterrumpidamente en el sendero del progreso que, aun plagado de obstáculos y desviaciones, le permite transitar con vehemencia en la rebusca de intereses mayores; ocurre así a la posesión de un sistema de vida mejor dotado de comodidades y seguridades que hace culminar en el régimen materialista donde se promueven como valores supremos la utilidad y la comodidad. En el extremo del sistema utilitario los valores pragmáticos reciben un mayor énfasis con el desbordamiento de la ambición y la imaginación, lo cual provoca el impulso creador que inspira las grandes realizaciones tecnocráticas de la civilización moderna. 


\section{Hacer, pensar y jugar}

En su multisecular recorrido la humanidad adquiere un abundante conocimiento que le permite determinar lo que hace y para qué lo hace; en ello está implicado el desarrollo de la conciencia y la similar evolución de los valores, de modo que en todo valor se finca un conocimiento, y viceversa. Hablando en rigor, el conocimiento acompaña desde un principio a todas las realizaciones de la humanidad, pues nada podemos hacer sin saber cómo hacerlo; esto explica por qué la incipiente existencia espiritual del homo sapiens se promueve a poco de haber iniciado su despegue utilitario el homo faber. Aquél permanece como depositario de la responsabilidad que implica el mantenimiento del progreso trazado por la especie humana desde su consagración como entidad pensante, en el umbral de un promisorio futuro donde se manifiesta y prevalece la capacidad de pensar.

La índole axiológica del género homo corresponde a la dignidad del homo sapiens, pero también existe un designio superior, mediante el cual se libera de la circunscripción limitativa de la utilidad y de las finalidades insertas en el conocimiento, accediendo al nivel sublime del juego, que implica el poder de generar los más diversos actos y obras para regocijo del espíritu, como un signo preclaro del poder por el poder, del saber por el saber y del hacer por el hacer, sin ningún propósito ulterior. Es entonces cuando se juega libremente con los elementos que integran la vida, y en último análisis con la vida misma, ocurriendo en su extremo a entenderla y realizarla con un afán especialmente infundido por los deseos del juego, donde se agita la máxima libertad de creación para obtener el supremo deleite del espíritu. Así se entiende la vida como juego libre y soberano del hombre, con el pleno dominio de sus recursos y sus facultades; el destino del juego vital radica, según esta soberana visión lúdica, en ascender del aprendiz de brujo que ha sido al desatar los elementos de la naturaleza, al gran mago que debe ser para manejarlos a su albedrío, porque en el juego de aspiración omnipotente se revela con máxima fidelidad la imagen inescrutable de la creación cósmica.

La exultante apoteosis de los valores espirituales y materiales define la dignidad epónima del homo ludens; creador de su propia libertad, juega con ella en un óptimo divertimiento que podría expresarse mediante la concepción de la vida como incitación al juego y del juego como justificación de la vida. La evolución de la humanidad a través de los siglos y los milenios permite situar de este modo, en una misma trayectoria, al homo faber, al homo sapiens y al homo ludens, como fases culminantes de un mismo desarrollo que se polariza en hacer, pensar y jugar. Son los reflejos evolutivos de una actitud universal consistente en fomentar necesidades y deseos para procurar las satisfacciones que inducen con creciente libertad al predominio del hombre para obtener complacencia y plenitud en el transcurso de su vida. 
C

EL ORIGEN ONTOGENETICO

\section{La ontogenia individual}

El origen filogenético del valor encuentra necesario complemento en el origen ontogenético, pues si aquél comporta la producción de valores en la especie humana, éste significa su generación en el ámbito individual; su estudio reviste capital importancia desde el momento que la vida, entendida de manera prístina, es siempre una vida individual. Recordemos que todos los seres somos indefectiblemente individuales, como también las cosas, objetos, actos y obras que se producen en la realidad. De ahi que el estudio del origen ontogénico induzca a la vasta problemática derivada de la singularidad intrínseca de los hombres y sus actos, directamente observados en la fuente connotativa de la experiencia.

Desde luego, existen caracteres comunes a la ontogenia y la filogenia; se trata de notas esenciales a todo valor, como es ante todo la satisfacción de necesidades materiales y de los requerimientos más sofisticados que comprenden toda clase de necesidades y deseos, cuya presencia ocurre en ambas dimensiones, la genérica o filogenética y la individual u ontogenética. A ello se debe que ambos enfoques se complementen de manera reciproca en el estudio del valor, aunque por razones que se expondrán ahora la relación indica una creciente importancia de la ontogenia. A medida que los intereses axiológicos son más evolucionados comportan un ingrediente de mayor singularidad, de modo que en el dualismo de caracteres similares y distintos que registra la naturaleza humana, tienden a preponderar los segundos como signo distintivo del individuo, cuyo más elevado destino consiste en ser él mismo, reafirmar su identidad y distinguirse de los demás.

El análisis ontogenético del valor consiste en indagar su origen individual, sin olvidar que todo individuo pertenece a la especie, pues en ella se incluyen los individuos que en forma mutable y efímera la constituyen. El origen ontogenético del valor apunta a la evolución que experimenta el ser humano como individuo, a los procesos que ocurren al cumplimiento de este designio y los productos que arrojan en la prosecución de los valores; también se advierte el resultado de la evolución multisecular de la especie, cuyos efectos se reflejan en el ámbito individual señalando un reflejo de la complementación reciproca a que nos hemos referido. De ahí proviene la existencia de numerosos aspectos naturales y biológicos que influyen poderosamente en la conducta individual y matizan en gran medida su problemática axiológica. 


\section{Determinismo y finalismo}

La presencia del valor se manifiesta diferencialmente en cada individuo y contrasta con el determinismo biológico que es predominante en la especie; asume un carácter esencialmente conciente o teleológico en la medida que obedece -o en principio debiera obedecer- no tanto a la acción de causas biológicas, deterministas, naturales y materiales, sino al creciente influjo de las finalidades espirituales deliberadamente concebidas a través de la predominante acción de la conciencia con objeto de enaltecer el sentido de la vida. En virtud de la conciencia se proyecta el ejercicio de la libertad para postular valores ideales frente a la realidad de la vida, en lo cual se origina la dualidad y al mismo tiempo la oposición que observamos en los grandes hemisferios configurativos del ser y la conducta del hombre: por una parte, el hemisferio filogénico, natural, biológico o determinista, y por la otra, el ontogénico, cultural, espiritual o finalista. Así tenemos las características distintivas en los

HEMISFERIOS DE LO HUMANO

$\begin{array}{ll}\text { Filogénico } & \text { Ontogénico } \\ \text { Natural } & \text { Cultural } \\ \text { Biológico } & \text { Espiritual } \\ \text { Causalista } & \text { Finalista } \\ \text { Determinista } & \text { Organicista }\end{array}$

La ontogenia del valor empieza por la adquisición del libre albedrío que supuestamente rige en la conducta individual y se desenvuelve mediante la integración de la conciencia axiológica que asume cada quien a partir de la tendencia natural a satisfacer las necesidades inmediatas de la vida. La evolución de los intereses humanos conduce al nivel más desarrollado que fomenta deseos y satisfacciones de rango espiritual; allf se observa un claro sentido teleológico, pues no obstante que en un principio la gran mayoría de los requerimientos planteados por el individuo ingresan al terreno de la supervivencia biológica, el desarrollo ontogenético apunta vigorosamente a un cambio de signo, por cuya virtud adquieren paulatinamente preponderancia las solicitudes del espíritu, y se consagran en un plano ideal sobre el ara de la libertad.

En este ámbito de progreso, los satisfactores axiológicos asumen una diferenciación que propende a exhibir el contexto individual en oposición al colectivo, de modo que las motivaciones personales cobran superior importancia en la insospechada variedad de experiencias que acomete el individuo en el seno de la comunidad. Con ello se establece la fecunda simbiosis sociocultural que permite sumar el concurso de los individuos a los aportes de la 
sociedad, y viceversa, propiciando la integración de la cultura en oposición y al mismo tiempo acoplamiento de individuo y sociedad.

\section{Necesidades y deseos}

La noción más generalizada, la primera que sale al paso cuando se trata de esclarecer el significado filogenético del valor, es la que induce a señalarlo como algo necesario, mientras el sentido ontogenético, mucho más evolucionado que el anterior, lo exhibe como algo apetecible; de ahí parte el distingo establecido entre necesidades y deseos como hemisferios concomitantes de los intereses humanos. La comprensión integral del valor gira de este modo en la órbita de intereses cuyos dos polos son las necesidades y los deseos, apuntando a su resolución en los satisfactores respectivos.

El hecho de atribuir el valor a los objetos capaces de suscitar la apetencia del hombre, confiere importancia intrinseca a las entidades que satisfacen los deseos producidos constantemente en la vida, más allá de las necesidades que en la modalidad de urgencias se presentan de manera continua y prioritaria. La inmensa mayoría de las necesidades planteadas por el hombre moderno son más bien apetencias que él mismo interpreta como necesidades, o convierte en tales cuando se acostumbra a ellas, porque estrictamente hablando, necesidades son únicamente las que atañen a la subsistencia. Nadie diría, por ejemplo, que el uso de vehículos lujosos, ropa a la moda, residencias confortables y toda la abundante parafernalia de refinamientos que se cultivan desde la antigüedad, sean estrictamente necesarios para subsistir; en cambio, representan satisfactores apetecibles porque constantemente incitan el apetito y acaban manifestándose como elementos indispensables de orden social, debido a la costumbre que de ellos se consagra en relación a deseos e intereses que constituyen la más frecuente motivación en la vida; de este modo, la implantación de requerimientos que no son estrictamente indispensables cubre la mayor parte de la existencia individual y colectiva.

\section{Necesidad de progreso}

Así funcionan los satisfactores desde que la humanidad empezó a producirlos e incrementarlos; como puede observarse, tienen un alcance mucho mayor que el concerniente al nivel básico de subsistencia, pues constantemente acudimos a la invención de necesidades porque enriquecen el interés por la vida. A tal efecto se acompañan los medios conducentes a su satisfacción; el concepto que deliberadamente empleamos al indicar que las necesidades se inventan, significa que no se descubren ni se padecen de manera forzosa, cual sucede en la condición filogenética de la naturaleza; en cambio, se introducen de manera un tanto artificial como elementos de variedad y enriquecimiento 
para vivir mejor. Obviamente, una vida que estuviera limitada a satisfacer las urgencias biológicas parecería intolerablemente limitada.

La infinita capacidad de invención que el ser humano desenvuelve a través del tiempo origina el progreso mediante el constante impulso que recorre desde las etapas rudimentarias del homo faber, hacia la madurez que apunta en el homo sapiens, para culminar en el superior estado que señalamos en el homo ludens; éste es, para nosotros, el rey de la civilización, el triunfador en la vida, el hombre que trasciende la satisfacción de necesidades y deseos para jugar con ellos en calidad de elementos complementarios y suplementarios que le confieren el más amplio sentido de creación y delectación a la existencia. El requerimiento de progresar constituye el supremo aliciente para vivir, pues matiza todas las necesidades en calidad de satisfacciones particulares cuyo desenlace ocurre en la incontenible tendencia a diversificar los cauces de la civilización y la cultura.

El fabuloso adelanto que registra la vida moderna obedece a que el hombre no se conformó desde un principio con existir precariamente para prevalecer apenas sobre las adversidades de la naturaleza; tampoco se resignó a obtener un nivel mínimo de seguridad y comodidad, en cuyo caso no habria rebasado el estadio del hombre primitivo. Trata, en cambio, de ampliar ilimitadamente su perspectiva superando los intereses que lo alientan mediante la producción y satisfacción de nuevas necesidades que desarrolla artificialmente para su propio deleite, y las multiplica hasta llegar inclusive a lo superfluo, al lujo y la ostentación que repetidamente se han censurado; todo ello corresponde a intereses muy complejos y va mucho más allá de la elemental exigencia biosociológica de sobrevivir. Gracias a la constante invención de necesidades la humanidad se sublima, y a veces se degrada, en aras de la personal apetencia para disfrutar los refinados goces de exacerbada complacencia que se contemplan a través de la historia.

\section{Apoteosis del poder}

El enorme volumen de satisfactores que llegan hasta la época actual revela que el hombre ha recogido la herencia depositada por las anteriores generaciones y se remonta con acelerado ritmo a cumplir el afán de enriquecer su vida, arbitrando toda clase de elementos, pero en primer término se muestra particularmente sensible a los que por antonomasia se designan con la palabra riqueza. Obvio es que los haberes crematísticos deben producir no sólo satisfacción, sino auténtico placer, y en último análisis propenden a justificar la innata tendencia que abriga cada individuo a preponderar sobre los demás; en su aspecto más justificable, la riqueza moderada se destina a cubrir las necesidades razonables, pero también se manifiesta el deseo de preponderar en forma ilegitima y forzada a base de poder, lo cual comporta con frecuencia 
el empleo de fuerza física y otras formas de violencia que se oponen radicalmente a la pristinidad de la esencia humana y la operabilidad de sus valores. El decisivo viraje en la historia se produjo cuando el hombre decidió que más allá del "yo necesito", predominante en las primeras etapas de su desarrollo, era posible afirmar el "yo quiero" y "yo puedo". Querer y poder fueron desde entonces las motivaciones arraigadas en su naturaleza, que refleja como instinto de poder, no sólo el que generalmente se interpreta como poder político sino un poder aún más trascendente que es el poder hacer, poder crear y poder dominar. Sentir que se puede lo que se quiere, se piensa lo que se siente y se domina lo que se tiene, es la fórmula suprema que justifica el hecho de vivir y le infunde un sentido de placer sublimado en los momentos de plenitud total.

Se diría que con el placer y el poder, el juego es la suprema motivación del ser humano; así como afirmamos antes que al momento de empezar a pensar se empieza a valorar, agregamos ahora que se empieza también a jugar, pues el juego se advierte como un instinto desarrollado desde las especies animales y obviamente se sublima en el género humano. Del juego deriva el triunfo y del triunfo la apoteosis de ser mejor que los demás; queremos vencer y hacer que nuestra voluntad se convierta en árbitro de ajenos destinos. La meta de todo juego es vencer y preponderar; esto es lo que justifica en último análisis el ingente deseo de progreso que alcanza el instinto de variedad, presente en el ritmo de las actividades y perspectivas que se persiguen en el curso de la vida.

La constatación de las motivaciones axiológicas constituye el umbral de la teoría a que deseamos llegar: el impulso ontogenético del valor experimenta una constante evolución a través de la tendencia que se constata como resorte animador de la vida, consistente en promover el aumento y variedad en necesidades y deseos para asumir el correspondiente incremento y la diversificación en satisfacciones y placeres; el hecho de vivir se colma con el mayor número de intereses y satisfacciones, lo cual deriva de la compulsión a incrementar y diversificar las vivencias. De este modo se incurre en una apoteosis de variedad experiencial donde coexisten los valores del espíritu con el interés del juego, el placer y el poder; las satisfacciones, seguridades y comodidades que proporciona la vida están representadas principalmente la época moderna como resultado de la multisecular evolución que le precede.

\section{Satisfacción y plenitud}

El progreso en la vida está determinado por el hecho de convertir cada necesidad en una satisfacción y cada deseo en una plenitud; la plenitud es el sentimiento que se experimenta al colmar los intereses que afloran como necesidades o deseos. Sin embargo, no se trata de un sentimiento absoluto, pues 
no vale siempre ni para cualquier objeto; tampoco persiste indefinidamente una vez que se ha obtenido. Aparece en situaciones peculiares cuando coinciden determinadas circunstancias en un ámbito limitado, o sea que la plenitud es relativa de acuerdo al requerimiento específico que satisface en cada caso; pero aun así, reviste capital importancia desde el momento que otorga el máximo valor conferible al decurso concreto de la vida, pues no obstante sus limitaciones se renueva y diversifica constantemente, prosiguiendo la tendencia a encontrar mayor satisfacción en cada uno de los objetos, cosas, personas, actos, obras, momentos o circunstancias que participan en forma determinante para generar el sentimiento de variedad que constituye el antecedente directo de la plenitud. Requerir plenitud en la vida equivale a entenderla y sentirla como saturada de intereses, deseos y satisfacciones de toda indole. Para ello entran en juego los más diversificados elementos que inventa o descubre el ser humano, incluyendo los que percibe tal como son dados en la naturaleza y los que él mismo concibe en alas de la imaginación.

Los satisfactores obran también como producto de su incrementada y diversificada capacidad de invención; por ello, la plenitud es un sentimiento que se apareja estrechamente al instinto de variedad; sabemos que pierde su auténtico sentido cuando la repetición, la inercia, el abandono, la monotonía o la indiferencia destruyen los mecanismos innovadores que fomentan el deseo y estimulan la necesidad.

En tal virtud se abre un horizonte infinito a las agudas solicitudes del temperamento, con la consiguiente capacidad de renovación que constituye la clave del progreso. Así se enriquece el abundante repertorio de experiencias que tienden a copar la vida en todos sus momentos, con sus numerosos aspectos y dimensiones de realización: los momentos más significativos, tanto en lo material como en lo espiritual, registran la plenitud que ocupa la cúspide en el proceso de la ontogenia axiológica, mientras el contrapolo está significado por la necesidad insatisfecha de variar constantemente el contenido vital, de suerte que el cenit conduce al nadir y viceversa, generando el proceso cíclico y recurrente que constituye la clave de la dinámica ontogenética del valor.

\section{La dinámica ontogenética}

El origen del valor en el fuero individual se manifiesta a través de una dinámica consistente en incrementar necesidades y deseos para ampliar proporcionalmente el horizonte de la vida; su posibilidad de cumplimiento indica que debemos crear nuevas necesidades para inspirar nuevos satisfactores, y así sucesivamente. La dinámica recurrente que denota la ontogenia axiológica auspicia la constante variación de las apetencias con el concomitante aumento de los satisfactores, ocurriendo en cada caso a una nueva diversificación de las 
primeras para obtener el proporcional enriquecimiento de los segundos. La experiencia que produce este recurso cíclico de la vida repercute en el placer y la plenitud, como está cifrado en el inexinguible instinto de variedad, renovación, poder y juego, lo cual se designa comúnmente como interés de vivir; los momentos culminantes del juego se traducen en la sensación de plenitud y poder, configurando el ímpetu de progreso que se experimenta a nivel individual y colectivo.

Todo ello es lo que llamamos genéricamente la dinámica ontogenética del valor, o sea el mecanismo básico que promueve la obtención y aplicación de los valores en el ámbito primordialmente individual. Así se explica el origen que asume el valor en la conciencia; el proceso en cuestión proporciona la clave para entender su permanente desarrollo, pues conlleva numerosas implicaciones; la dinámica ontogenética constituye, en todo caso, el resorte que promueve el progreso de los individuos y, por reflejo, de las colectividades. La evolución de la vida equivale a un constante cambio, hito irremplazable en la búsqueda de satisfacciones y progreso; mediante la vinculación de los elementos que lo constituyen se percibe claramente que, para progresar, lo primero que se requiere es cambiar, de modo que tan imperiosa como la necesidad de progreso es la urgencia de cambio, al punto de que ambos, como conceptos y actos, son indesligables.

La dinámica ontogenética del valor se desenvuelve enmedio de un agitado juego que agudiza cada vez más el interés en y por la vida, creando nuevas necesidades para implantar nuevas satisfacciones, que a la vez se traduzcan en mayores requerimientos y ofrezcan renovadas satisfacciones, asumiendo en sus puntos culminantes las correspondientes vivencias de alto nivel intelectual y emocional. El centro de gravedad en este proceso está representado por la completa satisfacción de un interés, lo cual auspicia el sentimiento de plenitud que se extiende a sendos hemisferios vitales, material y espiritual. Pero la plenitud es perentoria, pues tan pronto se adquiere empieza a languidecer con la tendencia a atenuar el tono vivencial; se agita por la necesidad de cambio, y a la vez reclama nuevas satisfacciones que conduzcan a la plenitud, y así sucesivamente. De ahí deriva el carácter dinámico que distingue a la vida humana y que hẹmos puesto de relieve en el mecanismo generador de los valores.

\section{El esquema básico}

El sentimiento de plenitud equivale a un estado de satisfacción total que ocurre en determinados momentos de la vida, los cuales suelen ser más raros que frecuentes, según el tono mental y emocional en que se encuentre el sujeto; pero la condición más común señala que existe una tendencia a hacer que tales momentos sean los más amplios y diversificados que sea posible; 
para lograrlo se prosigue en la condición normal del individuo que reposa en la conciencia objetiva del valor, apoyada mediante un desarrollo espiritual que también requiere una apreciable y efectiva satisfacción material. Este mecanismo sintetiza la posibilidad de diseñar un esquema básico por cuya virtud se desenvuelve la ontogenia axiológica, aplicando los conceptos que con mayor frecuencia señalamos para caracterizar esta clase de procesos; el esquema en cuestión constituye el núcleo de la dinámica ontogénica y es tan sencillo que se expresa en dos palabras:

\section{Necesidad $\rightarrow$ Satisfacción}

Al conseguir una satisfacción y la correspondiente plenitud se habría resuelto el problema axiológico del individuo; pero sabemos que no sucede así, pues en el momento en que obtiene determinada satisfacción crea automáticamente la necesidad de cambio, que equivale a crear la necesidad de una nueva necesidad; tal vez se renueve la que estaba satisfecha, lo cual es tanto como crear una necesidad nueva. Así se explica por qué el hecho de obtener una determinada complacencia resuelve el problema particular a que se refiere y puede ser más o menos importante, pero no agota el problema vital; la tendencia ingénita a que nos hemos referido impulsa a diversificar, renovar e incrementar los intereses en aras de la variación y el cambio; así responde la naturaleza humana al instinto que propende a la constante variación, por cuyo efecto se crean nuevas necesidades que a la vez reclaman nuevos satisfactores para producir los correspondientes estados de plenitud; a la postre se generan otras necesidades y se repite el mismo procedimiento formal que, de este modo, puede expresarse en el esquema un poco más amplio y elocuente que el anterior, donde se comprenden las siguientes fases:

$$
\text { Necesidad } \rightarrow \text { Satisfacción } \rightarrow \text { Progreso } \rightarrow \text { Plenitud }
$$

\section{Tonia y atonia}

El verdadero sentido de la dinámica ontogenética no se entenderá, sin embargo, al margen de otro impulso que interviene poderosamente en el juego de las sugerencias, preferencias, urgencias y apetencias que conducen a la plenitud; dicho impulso desempeña un papel contrario al que acabamos de indicar, pues la dinámica integral del valor se origina mediante la confrontación de dos fases o etapas opuestas, aunque complementarias, que designaremos con los nombres de tonia y atonia.

La tonía axiológica representa un estado de tono o tensión; la palabra tono, de la cual deriva tonía, significa precisamente tensión y equivale a fuerza, vigor y vida; ello explica por qué se llama tónico al elemento que 
supuestamente proporciona tales virtudes. Curiosamente, la palabra tonia no es usual, mientras tónico se emplea mucho, y la contraria, atonia, es muy frecuente; esta última equivale al estado de abandono, indiferencia o insatisfacción, con la falta de fuerza y vigor, de tensión o entusiasmo que le acompaña; por regla general la atonfa emocional se experimenta por el prolongado mantenimiento de un mismo tipo de vivencia o por alguna ruptura de la dinámica psicológica. En este punto necesario es confrontar nuevamente el mandato de la naturaleza humana, la cual indica que después de cierto tiempo cualquier sensación que se experimente puede provocar una reacción adversa al estado tónico, pues en tanto que comporta éste satisfacción y plenitud, aquélla significa abandono o desinterés, y en su extremo llega al hastío.

Eso es lo que se llama comúnmente acostumbrarse a algo, decrecer el interés por un satisfactor y terminar fastidiándose con alguna situación, vivencia, objeto, persona o circunstancia, que fue capaz de suscitar el deseo; se comprende por qué el segundo impulso resulta adverso al primero, que describimos hace un momento para generar la plenitud. Concluimos entonces que al implantar la satisfacción probablemente se llegue a la plenitud, pero el efecto de excesiva permanencia en un mismo estado de ánimo, originada por la prolongada sensación de tono, hace disminuir considerablemente el interés que profesa el individuo hacia al contenido que la habia motivado; la reacción de atonía señala inequívocamente un estado adverso de distensión y abandono, equivalente a la pérdida de interés y su negativa repercusión se traduce en el rechazo de los mismos elementos que anteriormente nos habían logrado interesar y a veces inclusive apasionar.

Los ingleses, que suelen reparar con bastante agudeza en las cuestiones humanas, usan dos palabras perfectamente avenidas para significar los estados de ánimo resultantes de la dinámica alternativa del valor; la etapa tónica equivale a stress, o sea la tensión agudizada en una actitud permanente de réacción frente a las motivaciones vitales, en tanto la etapa atónica se traduce en spleen, distensión clásica de la aristocracia británica que, por haber experimentado todo, habría perdido interés en todo. Así se confronta el hecho de que algún misterioso resorte de la naturaleza humana determina que actuemos como si experimentar algo más allá de cierto tiempo y con la falta sustancial de variedad, significa necesariamente la pérdida del interés. Se trata en el fondo de dos estados de ánimo que llamariamos universales, y por algo las palabras inglesas se aplican con propiedad en otros idiomas: tonia stress y atonia-spleen constituyen los polos significativos en el interés que aparece, desaparece y reaparece en todos los momentos de la vida. 


\section{El ciclo ontogénico}

Se comprende entonces a qué obedece el deseo de variación como sustrato del interés vital; apenas se extingue o atenúa por alguna causa, renace por otra e inspira la búsqueda de nuevas perspectivas, lo cual provoca la renovación de la dinámica; ésta presenta un ritmo recurrente y denota la aparición, desaparición y reaparición de sus elementos. Por ello será oportuno ampliar el esquema anterior, donde está señalado el sentido positivo o tónico del proceso, por otro más completo que incluya además el sentido negativo o atónico, pues las dos etapas constitutivas deben tenerse en cuenta con la totalidad de sus fases y momentos, como se observa en el diseño que incluimos a continuación:

CICLO ONTOGENÉTICO DEL VALOR

(Primer esquema)

I. Etapa tónica

Necesidad Satisfacción Progreso Plenitud

II. Etapa atónica

Costumbre Indiferencia Hastio Necesidad

Obsérvese que la última fase de la etapa atónica es la misma que la primera de la etapa tónica, en lo cual radica la posibilidad de establecer contacto para fundar de manera integral la naturaleza del ciclo; su dinámica se agiliza mediante el planteamiento de nuevas necesidades que dan cauce a nuevas satisfacciones para convertirse en nuevas vivencias de progreso y plenitud, las cuales provocarán otra vez la indiferencia y el hastío, etc. Se configura de este modo el esquema cíclico del juego axiológico, el ludus tonalis de la vida, que adopta básicamente el modo recurrente como razón de ser, aunque siempre con un tono distinto y preferiblemente mejor. Empleando conceptos musicales, diremos que el modo subsiste invariante, pero los tonos cambian en cada caso, de suerte que el juego tonal mantiene la presencia de un ritmo y una melodía, aunque cambien los tonos en que se producen.

El proceso no ocurre de igual manera en todos los individuos; cada quien posee una forma diferencial de ser y proyectar la sensibilidad, pero el mecanismo que hemos expuesto como representativo del ciclo ontogenético es lo bastante general para que podamos adoptarlo como criterio de explicación y desarrollo en la contextura empiriológica o caracteriológica del ser humano. Así encontramos la versión individual del apotegma que dice: ¡Renovarse 
o morir! En el orden filogenético la urgencia de renovación señala el destino evolutivo de las especies, y en el orden ontogenético proporciona la clave del interés en y por la vida. Debido a esta realidad, creemos que el esquema anterior es ampliamente ilustrativo, pero resultará más elocuente si ensayamos el diseño gráfico de la secuencia cíclica que comprende sus diversas fases para integrar el ciclo, a cuyo efecto las dispondremos en circulo, destacando los hemisferios pertinentes a las etapas respectivas:

\section{CICLO ONTOGENÉTICO DEL VALOR}

(Segundo esquema)

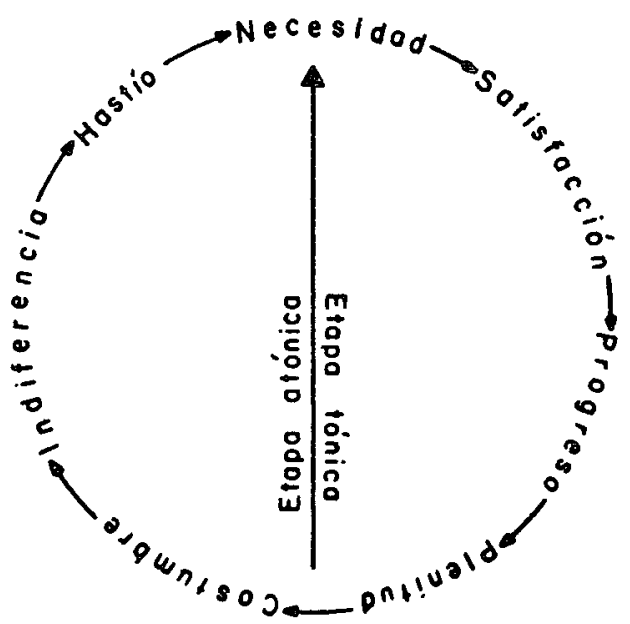

No es difícil advertir que en el orden filogenético y ontogenético se encuentran elementos de la naturaleza humana que determinan inexorablemente el origen del valor y participan poderosamente en su desarrollo al configurar las extensas regiones de influencia antropológica, psicológica y sociológica concernientes a las doctrinas que constituyen la explicación genética del valor, cifrada en la naturaleza humana. Ello no significa, sin embargo, que vayamos a recaer en el burdo individualismo que se advierte cuando al inquirir sobre un problema de valor se responde escuetamente: yo creo, yo siento, yo pienso, yo opino. La referencia subjetiva que interviene en la doctrina de los valores concierne básicamente a la naturaleza humana, y así debe entenderse en todo su alcance, teniendo en cuenta el postulado que considera al valor como expresión del hombre y al hombre como fuente y origen del valor.

\section{La ontogenia social}

Un mecanismo similar al que se constata en el ciclo ontogenético del valor concebido a nivel social se encuentra en el estrato de la conducta co- 
lectiva, desde el momento que los factores determinantes del comportamiento en singular influyen decisivamente para configurar la conducta en plural. Es así como la acción evolutiva de los pueblos acusa una serie de etapas que desempeñan la consiguiente función en la dinámica sociogénica, aunque la extensión de los períodos en la evolución social se mide por épocas históricas y es incomparablemente mayor que la duración de los lapsos individuales; mientras en éstos se registran duraciones breves que pueden llegar en su extremo hasta unos cuantos segundos, la evolución histórica de los pueblos señala cambios en la estructura y el comportamiento de la colectividad que se extienden a través de los años, los siglos y los milenios.

Lo primero que debe notarse en tal aspecto es el carácter alternante y recurrente que se observa en el conflictivo desarrollo de las colectividades, donde participan los factores racionales e irracionales que señalamos en la conducta individual, así como las etapas de auge y progreso que equivalen al estado de tensión dinámica o tonía, frente a otras de abandono y retroceso que comportan la distensión o atonía. Las causas que determinan esta conflictiva dinámica en la conducta social son muy variables, de modo que su estudio ocupa la atención de ciencias tan prominentes como la sociología, la antropologia, la historia y otras que en conjunto pretenden explicar a qué obedecen los signos peculiares del comportamiento masivo, contando para ello con la ingente participación de la filosofia en su peculiar acepción de filosofía social o filosofía de la historia.

A la base de este planteamiento se encuentra la formulación de un cierto denominador comunitario que orienta, distingue y caracteriza al comportamiento de los pueblos y se designa como conciencia colectiva, idiosincrasia grupal, comportamiento masivo, sentimiento comunitario y otras denominaciones equivalentes. Pero su formación exige que se produzca una amalgama en los diversos componentes que participan en ella y determinan la heterogeneidad básica que debe ser resuelta en la homogeneidad de la idiosincrasia social, lo cual requiere cierto tiempo para implantarse; pero una vez lograda se afirma con un peso especifico que constituye la inercia, bastante diffil de vencer en el ritmo del desarrollo, para procurar los cambios en la ontogenia social. Este es un problema muy importante que amerita ulteriores reflexiones.

\section{Importancia del progreso}

El ciclo axiogénico se repite constantemente a nivel individual y se refleja en el colectivo; este hecho auspicia que el esquema de la evolución axiológica sea también la base para explicar el desarrollo de la cultura y la civilización en aras de una dinámica donde participan activamente los elementos señalados: vivencias, preferencias, sugerencias, apetencias y urgencias; todas se 
correlacionan indisolublemente en la satisfacción y la plenitud, con el ingénito compulso a vivir cada vez mejor y siempre de distinta manera. La dinámica fundamental de la vida radica en la constante diversificación de sus intereses, lo cual incluye en primer término el ímpetu a obtener satisfactores en mayor cantidad y con la mayor variedad posible; he aqui el sostenido ritmo que se contempla como signo universal de la existencia en el inveterado anhelo de cambio y progreso, lo cual autoriza a formular la siguiente conclusión: quien no quiere progresar es porque nada desea y si nada desea es porque no quiere vivir.

El mejor camino para mantener el interés en y por la vida radica en la intensificación y diversificación de las vivencias, con la plenitud que otorga el hecho de manejar los elementos que participan en el juego de las expresiones y realizaciones creativas; son ellas el mejor aliento para remozar el transcurso altamente fecundo de nuestro existir, por lo cual la multiplicación de los intereses vitales, llámense necesidades o deseos, con las satisfacciones que proporciona, induce a postular la doctrina básica que sostenemos en torno el origen del valor, consistente en reconocer el indispensable requerimiento de multiplicar, diversificar y renovar las experiencias para progresar de continuo; vivir cada vez mejor equivale a vivir con mayor intensidad, porque en ello radica el interés peculiar de la vida. Al decir esto no descubrimos nada, pero de verdad tan consabida se desprende un principio universal para comprender e interpretar el origen del problema axiológico que inquieta poderosamente a la conciencia filosófica y cultural de nuestro tiempo.

\section{EL VALOR Y LO HUMANO}

\section{Universalidad del valor}

El examen que acabamos de efectuar permitió explorar el origen filogenético y ontogenético del valor, señalando la indisoluble relación que establece con los intereses humanos; sabemos que éstos pueden ser sustancialmente de dos tipos: necesidades y deseos, aunque es difícil acotar una frontera que los divida de manera tajante, pues la necesidad conlleva un deseo, y viceversa; en ambos casos, la satisfacción se encuentra en los valores producidos por el hombre $y$, de manera recíproca, los valores se originan como satisfacción a los intereses. Vimos también que los elementos precursores de la experiencia valorativa se localizan desde los tiempos más remotos y coinciden en el origen mismo de la vida, donde se constatan evolutivamente a partir de su más rudimentario nivel. Exploramos de qué manera la existencia se 
encuentra saturada por elementos que comportan un valor y se desenvuelven en el seno de la dinámica recurrente del ciclo ontogénico, lo cual también explica indirectamente, la prolongada evolución filogenética que adquieren los intereses en su reiterada expresión secular a través de los ciclos históricos de la cultura.

La conclusión que obtenemos de estas observaciones permite afirmar que la totalidad de la vida está rodeada por necesidades y deseos de la más diversa indole, los cuales requieren la producción de satisfactores, que a su vez comportan la generación de los valores concomitantes; por ello, la existencia humana resulta íntegramente explicable como una constante búsqueda y realización de satisfactores que la impulsan a cada momento. Así se manifiesta la indefectible presencia de la virtud que designaremos escuetamente como totalidad o universalidad del valor y representa el vértice donde necesidades y deseos convergen a la constante búsqueda de satisfactores que se generan en diversos niveles con las más variadas formas de realización; todos los actos y obras que constituyen el decurso esencial de la vida llevan a cabo, cada uno con sus peculiaridades especificas, esta indefectible misión: infundir un contenido de valor a la experiencia. La realidad de la vida humana es interpretable en calidad de experiencia axiológica pues la concepción y realización de los valores cubre de un modo $\mathrm{u}$ otro su transcurso y su contenido. Al cumplimiento de este propósito avanza la actividad desde los estados más simples que presentan las urgencias primordiales del vivir, hasta los requerimientos más elevados que comportan la máxima plenitud en la realización espiritual. Por ello, la relación entre lo humano y el valor se agudiza al punto de configurar una dimensión universal que determina el contenido de la vida como totalidad de los valores, y la totalidad de los valores como contenido de la vida, traducido este dualismo a las incontables polaridades del quehacer cultural y cotidiano que satura la existencia.

Todos los valores se llevan a cabo en el transcurso de la vida, en la cual, con la cual, por la cual y para la cual adquieren su verdadero significado; la totalidad de obras o actos donde se realizan constituye el universo axiológico, que viene a ser equivalente a la vida misma interpretada a través del valor. En la esfera integral de los valores asumen las limitaciones distintivas de cada caso, pero en conjunto se extienden en forma irrestricta como una cobertura total en la expansiva esfera que comprenden las facultades y actividades del hombre, cuyo núcleo determinativo se encuentra en la concepción y realización de lo que estimamos valioso.

\section{Totalidad de lo humano}

A partir de que los valores se manifiestan a través de los intereses, llámense necesidades o deseos, y se traducen a sus respectivas realidades, pode- 
mos afirmar que intereses y valores conllevan el conocimiento de los mismos; se refrenda así la repercusión universal que adquiere el saber en toda la amplitud de la vida humana y también la dimensión total que asume el valor, lo cual explica —entre otros aspectos- la decisiva importancia que señalaremos en el estudio de la epistemología, en paralelo a la similar trascendencia de su temática, pues ambas convergen al estudio de los valores.

De acuerdo al criterio que manejamos en este planteamiento, la vida puede entenderse como una continua experiencia de intereses que originan necesidades y deseos, lo cual por una parte requiere y por la otra produce, elementos de la más variada índole en correspondencia a la demanda de satisfacción; este mecanismo, consistente en plantear necesidades y deseos con el arbitrio de los respectivos satisfactores, proyectado al ámbito de la vida humana, es lo que entendemos por experiencia axiológica, cuyo alcance universal se justifica mediante la conclusión que obtenemos al definir el valor como término universal de relación con el hombre; ahora bien, esa misma tesis equivale a afirmar la ilimitada posibilidad de infundirlo como contenido en todos los actos, obras, proyectos, vivencias o experiencias, mediante la satisfacción de necesidades y deseos. Esto es lo que significa el apotegma que derivamos como conclusión de las observaciones anteriores: valor es todo lo humano y todo lo concerniente a lo humano.

La esencia operativa del valor está cifrada en su relación con los intereses del hombre y el significado que asume para el hombre mismo, de lo cual se desprende la diferencia que, a pesar de todo, subsiste entre ser y valer, así como la jerarquía que el valor adquiere sobre el ser, toda vez que la connotación del ser natural es insuficiente para explicar el sentido de la vida $\mathrm{y}$, por consiguiente, la existencia del hombre como un ser que se desenvuelve en ella con sus propios intereses, lo cual equivale a decir sus propios valores. Es posible afirmar, entonces, que la vida representa el desenvolvimiento de un constante afán por infundir en ella el contenido axiológico que se produce a cada momento en el infinito número de concepciones y realizaciones donde encarna el objetivo primordial, consistente en la satisfacción de sus intereses, de modo que la conclusión anterior puede complementarse con la recíproca: todo lo concerniente a lo humano comporta un valor.

\section{Las entidades axiológicas}

La realización de los valores se lleva a cabo en el transcurso de la vida, tanto a nivel individual como colectivo, según corresponde al doble origen ontogénico y filogénico del valor. La experiencia se desenvuelve, desde un punto de vista axiológico, mediante el cúmulo de actos, obras, objetos, seres, cosas, circunstancias, personas, ideas, proyectos, instituciones, imágenes, recuerdos, etc., que se encuentran a cada paso y cobran sentido axiológico por 
el estancamiento de una relación con el hombre, debido a que tienen o adquieren un significado para él, ya como producto suyo o porque establecen una vinculación con sus intereses.

La infinita gama de posibilidades que reviste la realización del valor reclama que encontremos un nombre común a todas las entidades en que se manifiesta; acuñaremos a tal efecto el concepto generalísimo de entidades axiológicas para designar todos los actos, objetos, etc., que de algún modo pertenecen al hombre o establecen una relación con él, incidiendo en su vida y sus intereses. Cada entidad axiológica implica la realización de un valor, por lo cual llegamos a una noción de la mayor importancia que manejaremos reiteradamente en el transcurso de estas reflexiones: entidades axiológicas son toda clase de elementos que pertenecen al hombre o guardan una relación con él.

\section{Conocimiento y valor}

Dijimos ya que para ser posible la realización del valor se requiere la presencia del conocimiento; los actos genuinamente humanos son aquéllos de los que tenemos conciencia, no los que efectuamos en forma mecánica o instintiva. Por ello afirmamos que el protorigen del valor apunta en el homo sapiens, y no podria ser de otro modo desde el momento que la esencia de la vida está cifrada en el conocimiento. Ahora bien, se ha definido al ser humano como animal racional definición que entraña una gran verdad no sólo por el contenido racional que se percibe en la naturaleza humana, sino también por la abundante herencia de animalidad que se constata en ella; de ahi que no sea reiterativo decir vida biológica o animal para fundar un distingo con respecto a la vida psicológica o espiritual que estimamos como netamente humana, aunque a decir verdad se encuentra en ella un abundante reflejo del componente animal.

Recordemos a tal respecto que el origen filogenético del valor se presenta bajo la forma de reacciones mecánicas o instintivas que pertenecen a la especie y entroncan en el origen mismo de la vida. Ahora debemos agregar que adquiere ella su definido carácter humano mediante el arbitrio de las nociones requeridas para conferirle una base de sustentación, significada por la conciencia de lo que somos y lo que hacemos, lo cual comporta el conocimiento necesario para vivir con un sentido humano, lo más humano que sea posible, vale decir, lo más racional y espiritual. Este conocimiento se establece de manera genérica en calidad de conciencia y podría definirse como base de la experiencia axiológica afirmando que: la conciencia del valor auspicia la experiencia de la existencia.

La intervención del conocimiento en el desarrollo progresivo de la vida adquiere una extraordinaria importancia para conferirle el carácter humano 
que, según hemos dicho, se distingue de la acepción biológica o natural en la medida que incorpora los elementos necesarios para darnos cuenta de lo que somos y lo que hacemos, para asumir la responsabilidad de nuestros actos en la perspectiva de evolución individual y colectiva, todo lo cual imbrica como elemento básico la conciencia del valor. Por ello, en lo sucesivo debemos entender a cada valor como una forma de conocimiento, y a cada conocimiento como una forma de valor; la implicancia mutua de ambos términos es ineludible y apoya, a la vez que condiciona, a la vida humana que, en tal sentido es resultado de la compresencia cognitiva y debe entenderse en calidad de experiencia. Esta última puede ser precisada como la existencia asumida a través de la conciencia. Concluimos entonces que no puede haber un verdadero valor si no tenemos el conocimiento de lo que significa, lo cual se logra a través de la experiencia; análogamente, la experiencia está fundada en la posibilidad de saber lo que los valores son y representan para nosotros. Los conceptos de conocimiento y valor son indesligables hasta el punto de que pueden identificarse en una conclusión que dice: todo conocimiento es un valor $y$ todo valor es un conocimiento.

\section{Existencia, conciencia y experiencia}

El conjunto de conocimientos que determinan la comprensión, explicación y realización del valor, es lo que en términos generales designamos como conciencia axiológica o conciencia del valor y su tratamiento constituye el tema de un capítulo especial; el planteamiento axiológico debe partir de lo que somos y hacemos, lo que sabemos y conocemos, lo que son la naturaleza y la conducta del hombre, lo que significa la experiencia para infundirle un sentido de valor que la encauce por el sendero del progreso.

Este problema permite efectuar un replanteamiento del valor vinculado en concreto a la experiencia axiológica, en forma tal que la noción básica del valor resulta asimilable a la homóloga noción de la experiencia del valor. $\mathrm{El}$ apotegma que se desliza en estas reflexiones es el siguiente: la vida humana representa una constante experiencia asumida a través de la conciencia. De este modo, el concepto del valor, el conocimiento del valor y la experiencia del valor, se identifican en su común origen y evolucionan de acuerdo al nivel de racionalidad que se pone de relieve en los diversos grados y modalidades del saber. La vida biológica se constituye como vida humana en la medida que pueda asimilar las vivencias mediante el ejercicio de la conciencia, de tal suerte que el solo hecho de existir se convierte en el acto más profundo de vivir, y recíprocamente, la vida vinculada a la naturaleza biológica asume un contenido psicológico de acuerdo al conocimiento que en ella ocurre. Las formas humanas de vida se caracterizan por poseer un cierto 
nivel de conciencia y su ejercicio asociado a la vivencia se denomina experiencia.

El concepto de experiencia denota el ser y el hacer del hombre, con el conocimiento de lo que es y lo que hace; la experiencia está constituida por todos los actos que conllevan el conocimiento de lo que somos y lo que hacemos, lo que son nuestros actos y obras, lo que significan para nosotros como un producto nuestro. Los conceptos de conocimiento y valor son indesligables, como también los de conciencia y experiencia; todos se vinculan indisolublemente como signos integrativos de la existencia, lo cual permite establecer el siguiente esquema para señalar la sensible analogía que existe en los conceptos implicativos del:

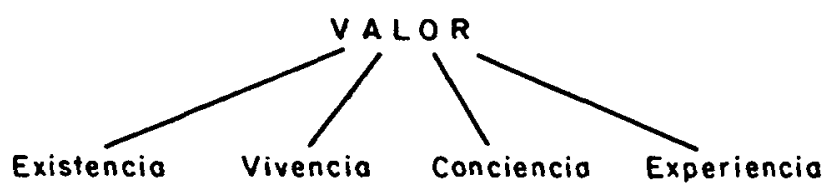

\section{Conceptos implicativos}

Manejando con cierta ductilidad los anteriores conceptos podemos establecer algunas definiciones equivalentes y complementarias que son de capital importancia en nuestra disciplina.

a) Vivencia. Es la existencia asumida a través de la conciencia y la experiencia.

b) Existencia. Es la vivencia proyectada en la experiencia por medio de la conciencia.

c) Conciencia. Es el conocimiento de la existencia percibida en la experiencia.

d) Experiencia. Es la existencia realizada en el valor que propicia la conciencia.

e) Valor. Es la correlación de la conciencia en la vivencia como experiencia de la existencia.

El indisoluble vínculo entre el valor y lo humano se establece sobre el común denominador del conocimiento; el valor desempeña primordialmente la función de faro regulador que dirige el sentido progresivo de la vida en aras de la permanente búsqueda para conferirle un carácter de satisfacción y plenitud, mediante el conocimiento y la realización de las finalidades trazadas en el desarrollo de la actividad, saturada por intereses de toda indole que permiten constatarla como una permanente experiencia del valor. De ahí la conclusión que obtenemos sobre esta perspectiva conjunta, referida al carácter humano del valor, que engloba la problemática de la axiología, o 
más ampliamente, de toda la filosofia; puede expresarse en el siguiente postulado universal: el contenido netamente humano de la vida está determinado por la experiencia del valor y se desenvuelve mediante el conocimiento que acompaña a la vida.

\section{Presencia de lo irracional}

Cierto es que el aspecto genuinamente humano de la vida radica en la racionalidad, pero también se manifiesta en ella su contrapolo, o sea un fuerte ingrediente de irracionalidad, el cual se constata de manera irrevocable en las vivencias que constantemente asumimos en forma mecánica o instintiva. La experiencia axiológica se promueve a través del camino alternante que incluye racionalidad e irracionalidad como elementos indefectiblemente presentes en cada uno de nuestros actos, aunque siempre se verifican en modalidades y proporciones variables.

Las diversas formas que tiene de presentarse la irracionalidad en los seres humanos es de lo más aleatorio; nadie hay que pueda consumar todos los actos con deliberación plena, hasta el punto de eliminar por completo los factores irracionales de la conducta. El ser humano está configurado por una abigarrada mezcla de ingredientes opuestos, racionales e irracionales, lo cual repercute en gran medida sobre la problemática crítica de la experiencia valorativa, integrada mediante la intervención de la conciencia racional frente a la acción irracional que ejercen los agentes instintivos, atávicos, biológicos, mecánicos, impulsivos, pasionales e imitativos, los cuales se heredan y desarrollan con la dinámica que envuelve a la experiencia individual en el seno de la sociedad.

El transcurso vital se caracteriza por la presencia de un permanente antagonismo donde se confrontan los aspectos racionales e irracionales, concientes e inconcientes, deliberados y mecánicos, ecuánimes y pasionales, equilibrados y conflictivos, en nuestra compleja naturaleza; los primeros se manifiestan en oposición a los segundos, de modo que la evolución del valor puede explicarse a través de la experiencia individual en el seno de la colectividad, mediante un esquema a cuya base actúa el resorte impulsor de las necesidades planteadas como recurso de subsistencia. Para contrarrestar la acción de los factores instintivos se ponen en juego los valores racionalmente sancionados por el individuo y la sociedad, los cuales desempeñan una función direccional y evolucionan hasta alcanzar el alto grado de complejidad que se constata en las etapas culminantes de la historia. Esta observación resulta de la mayor importancia para acometer la doctrina del valor a través de la experiencia, o sea la vida en su acepción concreta de conducta, desde el momento que se establece la participación de lo racional y lo irracional que, en cuanto factores indispensables, existen y coexisten en ella. 


\section{El valor como reflejo}

Nuestras consideraciones se aplican integramente para explicar el sentido dinámico de la experiencia axiológica; los aspectos irracionales e instintivos se ven alentados por la dinámica de la especie, mientras las actitudes racionales y concientes culminan en la conciencia individual y social, suponiendo naturalmente que se hubiera adquirido, con las restricciones que operan en cada caso.

Sabemos que la vida biológica exhibe, desde sus primeros niveles, ciertas posibilidades de capacidad electiva; la acción mecánica de los organismos unicelulares refleja el origen de una dotación instintiva que se transmite como herencia filogenética a través de las generaciones y culmina en los impulsos, tendencias, instintos, acciones y pasiones que configuran el hemisferio irracional del ser humano. De ah́ la imposibilidad de soslayar la poderosa influencia que ejerce la naturaleza biológica en la conducta y, por consiguiente, en la experiencia axiológica. Por ello, la vida psicológica se relaciona con la vida biológica y entrambas arrojan como fruto la experiencia axiológica. El valor es un reflejo de la naturaleza humana, compuesta por los dos mundos que integran nuestra realidad y que pueden distinguirse básicamente como:

a) Mundo irracional, instintivo, biológico o natural.

b) Mundo racional, conciente, psicológico o cultural.

La consecuencia del paralelismo que existe entre lo humano y el valor, asi como la determinabilidad ejercida por la naturaleza conduce a una im. portante conclusión que representa la tesis básica de nuestro trabajo, a saber: el valor es un reflejo de la naturaleza humana. La postura tendiente a interpretar esta naturaleza a través del valor y el valor a través de la naturaleza humana, proporciona uno de los criterios más fecundos para desarrollar la temática concerniente a la experiencia axiológica, determinada por la constitución humana y los valores trazados como metas para su prosecución. La doctrina que se deriva de esta doble perspectiva constituye una teoría antropológica del valor y puede conocerse llanamente como antropologismo axiológico, o también a la inversa, como axiologia antropológica, cuya cobertura abarca la totalidad de la vida.

$\mathbf{E}$

EL REPLANTEAMIENTO AXIOLÓGICO

\section{El ser y lo humano}

El mecanismo generador de los valores se funda, por lo que hemos visto, en su correlación con los intereses humanos, que a la vez derivan de su propia 
naturaleza ubicada frente a los objetos y circunstancias que envuelven la vida. $\mathrm{La}$ correlación entre lo humano y el valor indica claramente que cuando un objeto o entidad cualquiera ingresa en el ámbito de la experiencia, es explicable según los términos insertos en la naturaleza humana, cuya índole repercute en el cúmulo de intereses o actividades que genera de continuo y se traducen finalmente a la realización de los valores. Contemplado a la inversa el proceso de la experiencia, comprobamos que los elementos insertos en ella, provenientes tanto del mundo externo como del mundo interno, son interpretables en términos de valor. A tal efecto puede hablarse de un replanteamiento axiológico de los problemas que se confrontan en la experiencia, explicables y aplicables en la filosofía y la cultura, incluyendo asímismo los que surgen en la vida cotidiana. Gran parte de la axiologfa, y más ampliamente, de la interpretación axiológica de la vida, debe ocuparse en efectuar ese replanteamiento, a cuyo efecto empezaremos por el más clásico y universal de todos, o sea el problema del ser.

Prosiguiendo las derivaciones que implica el valor como término de correlación humana, observamos una similar a la que en ontologia tradicional considera la existencia del ser-en-si, lo cual comporta el concepto del ser entenido como independiente del hombre. Sin embargo, sabemos que este concepto es superado por la ontoepistemología crítica en base a las observaciones de la experiencia, que supone al ser como siendo en-mi, desde el momento que sólo tiene sentido en la medida que sabemos de él. Análogamente, la axiología tradicional propende a considerar la existencia de un valor-en-si, y lo entiende como entidad paradigmática y absoluta, aunque a la postre resulta insostenible ante el criterio de la moderna axiologia, en la cual se efectúa una crítica del concepto que considera al valor como independiente del hombre y lo presenta en calidad de un ente metafísico o paradigmático, a la manera de los prototipos lucubrativos, como existentes en un lugar determinado, que sería el topos uranus. Dicho concepto es, no sólo superable sino insostenible, y debe ser reemplazado por la acepción del valor-en-mi, entendido fundamentalmente a través de la múltiple correlación que se establece en el campo de los intereses humanos. Por ello, al concepto del valor-en-si debe oponerse la acepción del valor-en-mi, admitido tal como se incuba en el seno de la epistemologia critica. Esta tesis constituye el núcleo de la correlación axiogénica y conduce al establecimiento del valor en el orden funcional y conceptual, cubriendo los aspectos formal y material que se complementan reciprocamente en el proceso integrativo de la experiencia.

\section{La critificación axiológica}

Asi encontramos que el problema del ser puede y debe traducirse al problema del valor mediante la critificación que ocurre de acuerdo a las pautas 
metodologicas observadas en la axioepistemología, pues la problemática del valor se inspira en el similar proceso que previamente ocurrió en torno al ser y al conocimiento, con las inflexiones humanas inherentes a este nuevo replanteamiento axiológico, lo cual implica una profunda revaloración en las cuestiones del ser, el conocer y el vivir, generando el concomitante cambio en las coordenadas ontológicas, epistemológicas y antropológicas que determinan el sentido de la experiencia.

De este modo, el concepto del valor se precisa directamente en términos de genealogía humana, de manera similar a como ocurre con el planteamiento del ser en el seno del conocimiento y de los valores, en el ámbito de la cultura. Así llegamos a concluir que el valor es el conducto óptimo para obtener la deseada cosmopsicovisión, no sólo por su inversalidad intrínseca, debido a la inexcepcional presencia del valor, sino también por la correlación que se establece con respecto a los conceptos del ser y el conocer. La conclusión básica que obtenemos ahora señala que la índole del ser es trascendible en cuanto concepción netamente ontológica desde el momento que se manifiesta incluida en la noción epistemológica y antropológica; también es superable en el seno de la cosmopsicovisión axiológica donde se expone por modo directo y universal la presencia de los intereses humanos.

El núcleo del problema se localiza en la identificación que establecimos al principio entre lo humano y el valor, la cual proviene a su vez de una similar identificación prelativa y alternativa entre lo humano y el ser, lo humano y el conocer, lo humano y el vivir. Esta tesis prosigue en sus lineamientos básicos la inflexión generada por el idealismo crítico al esclarecer la dependencia de los objetos con respecto a la idea, y ahora agregamos la dependencia de la idea con respecto al valor, de modo que éste se proyecta al señalamiento de la cosmopsicovisión axiológica, o sea el concepto universal del mundo y de la vida contemplado a través del valor. Obvio es que en ella se finca la dependencia del ser y del conocer con respecto al valer, que a la vez deriva genéricamente de los intereses humanos. Así llegamos a la condición esencialmente crítica, antropológica, metodológica y formal, que justifica a la axiologia como base para obtener el concepto universal del mundo y de la vida, contemplado e interpretado a través del valor.

\section{Del ser al valor}

Ello no significa que las atribuciones ontológicas desaparezcan, pero deben explicarse de la mejor manera bajo la óptica del valor, que a la vez presupone los conceptos del conocer y el vivir, además del primigenio concepto del ser. En tal virtud, todo lo que tiene algún sentido para nosotros lo adquiere porque se relaciona con nosotros mismos, ya sea en el hecho de conocerlo o porque sirve a nuestros intereses, o por ambas razones, pues la depen- 
dencia con respecto al hombre se registra en los aspectos ontológico, epistemológico, antropológico y axiológico, desde el momento que el conocimiento implica una correlación de valor en razón directa de los intereses humanos, del conocimiento y la verdad que expresan, pues obviamente la verdad constituye el contenido característico del conocimiento y es también el valor básico en la vida.

El sentido de la experiencia valorativa nos dice que cada uno de los atributos ontológicos se explica epistemológicamente, se asimila antropológicamente y se desarrolla axiológicamente, englobando en cada caso las aplicaciones que encuentra en su relación con el hombre. Cualquier objeto real mantiene el sentido ontológico inherente a su propia naturaleza, pero a través de la experiencia se convierte de un ser en un conocer, en un vivir y en un valer, de modo que exhibe tantos valores como funciones de conocimiento posee, y como necesidades satisface, o se desempeña como correlato de intereses en su múltiple relación con el hombre. Merced a este proceso transitamos del ser al valor mediante el conocer y el vivir; la realidad ontológica se erige en realidad epistemológica, antropológica y axiológica, de análoga manera a como la problemática tradicionalmente acogida en la ontología se convierte en un planteamiento homólogo para la epistemología, se traslada con un sentido más amplio a la antropología y alcanza la máxima dimensión en la axiologia. Estas observaciones se aplican a cualquier objeto, cosa, entidad o circunstancia que quiera traerse a colación, pues la posibilidad de fincar un vínculo de valor con los objetos a través de la experiencia humana es universal.

\section{El replanteamiento axiológico}

Las consideraciones anteriores abren la compuerta para llevar a cabo la explicación del valor, entendido como fundamento de la cosmopsicovisión universal; para ello es necesario efectuar un examen más amplio de la equivalencia ontológico-epistemológico-antropológico-axiológica, lo cual conlleva en primer término la justa y realista comprensión de la experiencia valorativa como reflejo y superación de la experiencia antropológica y epistemológica, aś como de la ingenua experiencia ontológica entendida en el sentido clásico; también figura en este enfoque el replanteamiento de la temática tradicional que puede ser retomada mediante la indoctrinación crítica, teniendo en cuenta el síntoma fenoménico de la recurrencia cíclica en la problemática homóloga acaecida en cada etapa agógica de transición histórica.

Al proseguir la pauta exegética de la experiencia axiológica para llegar a la interpretación axiomática en paralelo a la evolución genética y teorética del valor, transitamos de la acepción pragmática que responde a los intereses 
cotidianos del vivir para acceder al trascendental nivel de la experiencia cultural, donde se exponen en forma de actos y obras las elevadas expresiones del espíritu. Todo ello se traduce en una secuencia paralela de conceptos ontológicos, epistemológicos, antropológicos y axiológicos, donde se localiza el sucedáneo doctrinario similarmente expuesto en cada uno de dichos renglones con respecto a los demás. De ahí surge el tratamiento isomorfo que se refleja en la axiologia con el manejo de cuestiones anteriormente expuestas en la ontologia, critificadas por la epistemologia, generalizadas por la antropologia, para culminar en el concepto universal y totalizante de la axiología, todo lo cual determina la subsunción ontológico-epistemológico-antropológicoaxiológica que constituye la clave para la explicación de este proceso a partir de los correspondientes niveles de la experiencia.

\section{La subsunción aporética}

Debido a esta condicionalidad critificante, se comprende el conjunto de las disciplinas tradicionales que acogen diversos planteamientos; ahora los podemos identificar como axiológicos, aunque durante mucho tiempo asumieron la denominación especifica de las ciencias respectivas en el campo de la filosofía, o de cualquier indole, tratándose de las ciencias particulares. En tal sentido ha operado el proceso que denominamos subsunción aporética y se vincula a la metátesis aporética; nos ocuparán ambos procesos con posterioridad, pero diremos por lo pronto que el significado de la subsunción estriba en la necesidad de proseguir la experiencia asumida en su evolución histórica mediante el tránsito de los problemas inicialmente acogidos en el manto de la ontologia, con el planteamiento del ser, después en la epistemología abocada el estudio del conocer, más tarde en la antropología cuya tarea se afoca básicamente al vivir, y todo ello culmina en la axiologfa con la problemática del valor. La metátesis aporética comporta, en cambio, la correlación temática de la filosofía, considerada genéricamente con las ciencias particulares y los problemas especificos, de modo que las cuestiones originalmente planteadas en la filosofía se trasladan después a las ciencias para su tratamiento experienrial, excluyendo los aspectos epistemológico y antropológico reintegrados a la filosofía mediante la critificación aporética y metodológica que se efectúa en el manto doctrinario de la crítica, que en la época actual presenta la nueva perspectiva de universalidad constatada a través de la axiologia.

Las tesis ontológicas, epistemológicas y antropológicas registran una homóloga secuencia de variantes doctrinarias, de modo que cualquier teoría axiológica puede considerarse como reflejo de una similar doctrina ontológica, epistemológica y antropológica, teniendo en cada caso como base los conceptos universales respectivos. La diferencia especffica que asiste a la experiencia del valor se expresa en relación a los intereses culturales del hom- 
bre; por ello encontramos en la axiologia una gran cantidad de problemas que han sido anteriormente expuestos en otras disciplinas, como sucede, por ejemplo, con las tesis del empirismo, el materialismo, el idealismo, el criticismo y demás ismos que se integran a partir de la correlación objetivosubjetiva y se proyectan a través de la historia con las respectivas ideas del ser, al conocer y el vivir, aunque ahora encuentran, por análogos motivos, una nueva modalidad en el apoyo que proporciona el concepto universal del valor.

Este hecho explica por qué la pluralidad doctrinaria subyacente en la axiologia se manifiesta mediante sus diversas posturas que existen como reiteración de una temática similar correspondiente al conocer y al vivir, de modo que nuestra disciplina se puede contemplar desde un ángulo susceptible de recibir determinaciones homólogas a las que se formulan en diversas épocas y con variados sistemas en las diversas ramas de la filosofía, repercutiendo en la ontología, la epistemología y la antropologia; de manera recíproca, la critificación axiológica revierte a los anteriores planteamientos, cuya común explicitación se encuentra en la génesis sistemática de las posturas filosóficas.

Cualquier ejemplo que quiera aducirse verificará la posibilidad de convertir las tesis sustanciales de las doctrinas ontológicas en epistemológicas, antropológicas y axiológicas, sobre la base de esgrimir el mismo concepto fundamental y verificarlo en cada caso mediante la aplicación de las categorfas respectivas. En rigor, se trata de un solo planteamiento formal que corresponde genéricamente a la teoría de la experiencia y tiende a verificar el concepto clásico de la filosofía, cuyo enlace estriba en obtener la cosmopsicovisión universal contemplada desde cuatro posiciones distintas. Así llegamos a la conclusión de que todos los objetos poseen determinadas propiedades naturales -ontologia-, pero adquieren sentido para nosotros en la medida que los conocemos -epistemologia-, figuran como contenido de nuestra experiencia vital —antropologia - y comportan un valor por los atributos que les confiere su diversificada correlación con los intereses humanos 一axiologia.

\section{El valor y lo humano}

Por lo que hemos visto, la gran mutación experimentada por la teoría de la experiencia en la historia filosófica está cifrada en el replanteamiento del problema universal que registra el tránsito del ser al conocer, al vivir y al valer, mediante la dependencia asumida por los tres primeros frente al último, en el cual se origina la auténtica doctrina universal del mundo y de la vida configurada a través de la experiencia y del valor, en paralelo al similar concepto que opera en torno a la universalidad del valor mismo. El distingo de dichos planteamientos se localiza en el primado humanista, o sea la atri- 
bución del hombre como centro de gravedad de la experiencia, mediante el filosofar y la cosmopsicovisión obtenida por su conducto. Así se produce el replanteamiento crítico de la temática clásica; el ser es interpretado en principio como naturaleza existente con independencia del hombre, sin embargo, la critificación de la doctrina realista, ocurrida desde las polémicas gnoseológicas y antropológicas de la época socrática, admite que los objetos de la realidad, aunque sean independientes del hombre, sólo pueden ser conocidos en la medida que ingresan al marco de referencia impuesto por las determinaciones epistémicas y genéricamente antropológicas, lo cual significa, en palabras más simples, que el ser existe para nosotros sólo en la medida que lo conocemos, y lo conocemos en la medida que nos relacionamos con él a través de la experiencia.

De esta suerte, las categorias del conocer actúan como determinantes sobre las categorfas del ser y se reflejan en las categorías del vivir; lo propio acontece con el valor, el cual denota para nosotros la categorfa universal por excelencia, inserta inequívocamente en la esfera omnicomprensiva de los intereses humanos, por cuya virtud se produce la reconsideración axiológica del ser en base al replanteamiento epistemológico y antropológico del conocer y el vivir; de este modo concluimos que, así como la existencia real del ser f́́sico significa en la etapa crítica de la historia superar la noción tradicional del ser-en-si, la doctrina crítica y trascendental del valor comporta el reconocimiento del valor-en-mi, o sea: lo que es del hombre, en el hombre, con el hombre, por el hombre y para el hombre.

Al señalar este hecho incidimos en el problema que interesa medularmente a la axiología: fundar el concepto universal del valor y diseñar el esquema del universo axiológico, lo cual nos ocupará en el siguiente capítulo. Este universo es discernible en virtud de la relación universal que se establece con los intereses humanos, en cuya virtud es posible afirmar la tesis que sostenemos en el sentido de que: valor es todo lo humano y todo lo que guarda relación con lo humano. El concepto del valor no tolera ninguna connotación metafísica; a tal efecto no tiene sentido suponer la existencia de un valor-en-si, desde el momento que por definición todo valor es un valor-en-mi; el valor reduce la entitatividad metafísica del ser-en-si, y lo incorpora a la relación humana que está imbricada en la idea funcional y correlacionante del valor. Por ello, el célebre lema de Terencio: Humano soy y nada humano me es ajeno, puede complementarse con este otro: Humano soy y nada que guarde relación con mis intereses puede serme ajeno. La segunda proposición enfatiza que lo humano se comprende por conducto de los intereses que comportan el valor, y no como en la acepción ontológica, por conducto de las cosas que representan al ser; asf se justifica el hombre como valor por medio de sus valores y no como objeto enmedio de los objetos. La descosificación del valor equivale a la descosificación del hombre; por ello constituye la base 
para el establecimiento de la doctrina genuinamente humanista que reconoce al universo como valor y al valor como universo, vale decir, como concepto universal del mundo y de la vida, indefectiblemente referido a los intereses y la esencia del hombre.

Miguel Bueno

INSTITUTO DE INVESTIGACiONES FilosóficAs

Universidad Nacional Autónoma de MÉXico 